\title{
RE-EVALUATING SUSTAINABILITY OF MICROFINANCE INSTITUTIONS BY USING TOPSIS
}

\author{
Muhammad Saad ${ }^{1}$, Hasniza Mohd Taib ${ }^{2}$, Abul Bashar Bhuiyan ${ }^{3}$ \\ ${ }^{1,2}$ Department of Finance, School of Economics, Finance and Banking Universiti Utara Malaysia, 06010 UUM Sintok, \\ Kedah, Malaysia, ${ }^{3}$ Faculty of Business and Accountancy (FBA) University of Selangor (unisel), Malaysia \\ Email: ${ }^{1}$ siddiquie011@gmail.com, ${ }^{2}$ hasniza@ uum.edu.my, ${ }^{3}$ bashariuk @ gmail.com
}

Article History: Received on $25^{\text {th }}$ February 2019, Revised on $28^{\text {th }}$ March 2019, Published on $25^{\text {th }}$ August 2019

\begin{abstract}
Purpose: The measurement of sustainability for microfinance institutions (MFIs) has been a serious problem for both practitioners and researchers over the last few decades. A multicriteria decision-making approach is used to develop an index that measures the sustainability of microfinance institutions based on the double bottom line.
\end{abstract}

Methodology: The sustainability score of MFIs operating in Pakistan for the year 2006-2015 is measured using the technique for order preference by similarity to ideal solution (TOPSIS). During the assessment, equal weights are assigned to all indicators of sustainability. Additionally, a hypothetical organization was assigned the industry threshold to generate composite scores using TOPSIS. Later, sustainability levels of individual MFIs were compared with this industry threshold.

Findings: Microfinance institutions that attain higher financial sustainability and positive outreach are ranked high. The result shows that the threshold sustainability level of the microfinance sector in Pakistan from 2006-2015 was 23.52, $26.31,23.80,45.83,45.83,66.67,77.77,91.60$, and 88.88 percent respectively. Although the sustainability level in 2015 decreases with respect to 2014, still the overall growth of the sector is remarkable. Practical implications: The results obtained from TOPSIS for evaluating the sustainability of MFIs under the double bottom line highlight its practical applicability. MFIs are under immense pressure by regulatory bodies, investors, donors, and financial experts to achieve sustainability. This index would help MFIs to track progress and improve their sustainability.

Novelty/Originality: This study is the first of its kind to determine the sustainability of MFI by using all the four indicators of sustainability, including financial self-sufficiency, operational self-sufficiency, depth of outreach and breadth of outreach. Existing sustainability indicators does not provide the threshold level of sustainability. Instead, they provide a ranking of MFIs from top to bottom only. This study is novel to identify whether MFIs have met or failed to achieve sustainability by providing the threshold level.

Key words: sustainability, microfinance institutions, TOPSIS, sustainability index.

\section{INTRODUCTION}

Sustainability of Microfinance institutions (MFIs) seeks to ensure that MFIs attain financial and operational selfsufficiency, and reach the maximum number of those deprived people of the society, attaining a 'double bottom-line', who are usually ignored by the conventional financial institutions (Hermes et al., 2011; Louis and Baesens, 2013; Rismayadi and Maemunah, 2018; Riyanti, 2018). This has led to the need for a measuring system that tracks the progress of sustainability over time (Rai and Rai, 2012; Mia et al., 2015).

The academic literature provides several pieces of evidence of attempting to develop indicators for predicting, ranking and measuring the sustainability of MFIs (Christen, 1995; Okumu, 2007; Rai and Rai, 2012). Indicators such as financial self-sufficiency, operational self-sufficiency, and outreach, measure financial and social sustainability. The subsidy dependence index (SDI) by Yaron (1994), Financial self-sufficiency (FSS) by Christen (1995), Operational selfsufficiency (OSS) by Okumu (2007), determines the most sustainable MFIs concerning a subsidy, financial, operational and outreach dimensions. The financial self-sufficiency and operational self-sufficiency have been identified as the key indicators for sustainability by CGAP (2003) and MFIs who are seeking investors' attention, proudly report their annual FSS and OSS ratios to highlight their sustainability performance.

Several researchers have criticized the applicability of existing measures of sustainability. Nanayakkara (2012), argues that the reliance on SDI is not acceptable as it indicates the dependence level of subsidies only and it may deviate MFIs from its mission of poverty alleviation as poor customers are charged with a high interest rate. Moreover, there is a strong disagreement on the financial and operational self-sufficiency measures of sustainability as these measures mainly focus on the financial aspects, ignoring the social dimension of sustainability. The same has been criticized by Bhanot $e t$ al. (2015), who stated that merely focusing on financial measures and ignoring the outreach measure deviates MFI from its original mission. There is a need to develop the sustainability measure which considers both financial and outreach measures. In an attempt to develop the sustainability index, Bhanot et al. (2015) used operational self-sufficiency and outreach measures but dropped the financial self-sufficiency, which is an important measure to determine whether MFIs can generate revenues to continue its operation without depending on subsidies. Additionally, the scope of their study was limited to only determining the sustainability scores of MFIs. 
Lancker and Nijkamp (2000), strongly argues that only measuring the sustainability score does not indicate anything, unless it is compared with a threshold or reference value. It is useless to rank MFIs based on their sustainability scores only as there are chances that all of them may have poor performance, holding the lowest standards. Additionally, the organization with the highest rank may not necessarily be considered sustainable unless a threshold is defined. Arrow et al. (2012) also suggest that firms are considered sustainable when their performance is improved or maintained with time. This indicates that passing the minimum acceptable or threshold level is one of the conditions for firm sustainability. The lack of threshold or base value in a sustainability index is an important issue that needs to be addressed. In this paper, a threshold or base value for the sustainability of MFIs is measured by holding the view of Lancker and Nijkamp (2000), and the method proposed by Afful-Dadzie et al. (2016). Multi-criteria decision-making (MCDM) method is used in this study to develop the composite measure for the sustainability of MFIs, by using a technique for order preference by similarity to ideal solution (TOPSIS) proposed by Hwang and Yoon (1981).

In TOPSIS, alternatives are simultaneously evaluated based on benefit and cost criteria. Good performing MFI is the one which is more close to the highest score of the index and far from the lowest, whereas bad performing MFI is near to the lowest level and far from the best score (Bilbao-Terol et al., 2014; Rosli and Siong, 2018; Rotova, 2018). More specifically, TOPSIS is based on the alternative distance from two hypothetically created reference points, also called the ideal positive and ideal negative. The best alternative has the shortest distance from the ideal positive and maximum distance from the ideal negative point (Wanke et al., 2016). Additionally, TOPSIS has been widely used in industrial applications and accepted by academia (Shih et al., 2007).

Review of previous literature provides several pieces of evidence for the application of TOPSIS, but they have different perspectives compared to the current study. Bhanot et al. (2015) used TOPSIS for determining the sustainability score of MFIs in India, while Wanke et al. (2016) used a two-stage TOPSIS for efficiency measurement of the Malaysian Islamic banks. Boran et al. (2009) used the intuitionistic fuzzy TOPSIS technique for supplier selection. Additionally, Deng et al. (2000) used the TOPSIS method for inter-company comparison process and empirically tested for seven firms in the textile sector of China. These highlighted studies have used several modified measures of TOPSIS for ranking of firms or suppliers.

In our analysis of related literature, the approach used by Afful-Dadzie et al. (2016) is similar to the TOPSIS method proposed in this paper for ranking. In this approach, sustainability scores are obtained, and MFIs are ranked accordingly. Moreover, a threshold for the sustainability of MFIs is generated to determine their sustainability level. This study is the first of its kind to determine the sustainability of MFI by using all the four indicators of sustainability, including financial self-sufficiency, operational self-sufficiency, depth of outreach and breadth of outreach. Additionally, no such study is found in the literature to determine the threshold for the sustainability of MFIs.

The remaining section of the paper is organized as follows. In the first section, the TOPSIS model is presented whereas the second section presents the method for measuring the sustainability threshold. Next, a numerical example of the TOPSIS method for MFIs is provided and is accompanied by the sustainability performance of MFIs in Pakistan for ten years. Conclusions and future research directions are then proffered.

\section{Performance ranking using TOPSIS}

Formally, the element of a decision matrix, $x_{j}^{k}$ is developed where $\mathrm{j}=1,2 \ldots ., \mathrm{m}$ and $\mathrm{k}=1,2, \ldots, \mathrm{n}$ as shown in Table1. Alternatives of the decision matrix are represented by a set of $n$ alternatives, $I=\left\{I^{k} / k=1,2, \ldots, n\right\}$ and criteria are presented by a set of $\mathrm{m}$ criteria, $\mathrm{C}=\left\{c_{J} / \mathrm{j}=1,2, \ldots, \mathrm{m}\right\}$, and the relative weights associated with these criteria are presented by $\mathrm{W}=$ $\left\{w_{J} / \mathrm{j}=1 ; 2 ; \ldots ; \mathrm{m} ; \sum_{j=1}^{m} \quad w_{J}=1\right\}$.

The element $x_{j}^{k}$ of the decision matrix provides the rating of kth alternative with respect to $\mathrm{j}$ criterion whose weight $w_{J}$ is assigned depending upon its importance. The decision matrix provides information for ranking an alternative in the matrix through the following steps;

Step 1: constructing normalized decision matrix.

Firstly, a normalized decision matrix $\mathrm{R}$ is constructed in which dimensional criteria $x_{j}^{k}$ is transformed to a nondimensional criterion. The normalized decision matrix $r_{j}^{k}$ is measured as:

$$
r_{j}^{k}=\frac{x_{j}^{k}}{\sqrt{\sum_{k=1}^{n}\left(x_{j}^{k}\right)^{2}}}, \quad \text { for } j=1,2 \ldots \ldots, m \text { and } k=1,2 \ldots, n
$$

Step 2: obtaining a weighted normalized decision matrix $\left(v_{j}^{k}\right)$

The normalized decision matrix is transformed into a weighted matrix in such a way that each criterion is assigned a weight relative to its importance. Weighted matrix $v_{j}^{k}$ is obtained when the normalized element $r_{j}^{k}$ is multiplied by its weight $w_{j}$ and is presented by equation (2) 


$$
v_{j}^{k}=w_{j} r_{j}^{k}, \text { for } k=1,2 \ldots, n \text { and } j=1,2 \ldots, m
$$

Table 1: Decision Matrix

\begin{tabular}{ccccc}
\hline & \multicolumn{2}{c}{ Criteria } & & \\
\hline Alternatives & $c_{J}$ & $c_{2}$ & $\cdots$ & $c_{m}$ \\
$I^{1}$ & $x_{1}^{1}$ & $x_{2}^{1}$ & $\ldots$ & $x_{m}^{1}$ \\
$I^{2}$ & $x_{1}^{2}$ & $x_{2}^{2}$ & $\ldots$ & $x_{m}^{2}$ \\
$\vdots$ & $\vdots$ & $\vdots$ & $\vdots$ & $\vdots$ \\
$I^{n}$ & $x_{1}^{n}$ & $x_{2}^{n}$ & $\ldots$ & $x_{m}^{n}$ \\
Weight $(\mathrm{W})$ & $w_{J}$ & $w_{2}$ & $\ldots$ & $w_{m}$ \\
\hline
\end{tabular}

Step 3: determining the ideal positive $\left(\mathrm{I}^{+}\right)$and ideal negative $\left(\mathrm{I}^{-}\right)$solution.

In TOPSIS, ideal positive and ideal negative points are hypothetically generated to be used as a comparison yardstick. An alternative that is closer to ideal positive $I^{+}$has the higher rank, and the alternative close to ideal negative $I^{-}$has the lowest rank. Let us consider that the set of negative (less is better) and positive (more is better) criteria be denoted by $\mathrm{J}^{-}$, and $J^{+}$. By using matrix $\mathrm{R}$, the ideal solutions are computed as:

$$
\begin{aligned}
& I^{+}=\left\{v_{1}^{+}, \ldots \ldots \ldots \ldots, v_{m}^{+}\right\}, \quad \text { where } v_{j}^{+}=\left\{\left(\max _{k} v_{j}^{k} \mid j \in J^{+}\right),\left(\min _{k} v_{j}^{k} \mid j \in J^{-}\right)\right\} \\
& I^{-}=\left\{v_{1}^{-}, \ldots \ldots \ldots \ldots, v_{m}^{-}\right\}, \quad \text { where } v_{j}^{-}=\left\{\left(\min _{k} v_{j}^{k} \mid j \in J^{+}\right),\left(\max _{k} v_{j}^{k} \mid j \in J^{-}\right)\right\}
\end{aligned}
$$

Step 4: Use Euclidean distance for computing separation measures.

In the next step, m-dimensional Euclidean distance is used to compute the separation measures. The separation measure from ideal positive denoted by $S^{k^{+}}$and from ideal negative denoted by $S^{k^{-}}$are measured as:

$$
\begin{aligned}
S^{k^{+}} & =\sqrt{\sum_{j=1}^{m}\left(v_{j}^{+}-v_{j}^{k}\right)^{2}, \text { for } k=1,2,3 \ldots \ldots, n} \\
S^{k^{-}} & =\sqrt{\sum_{j=1}^{m}\left(v_{j}^{-}-v_{j}^{k}\right)^{2}, \text { for } k=1,2,3 \ldots \ldots, n}
\end{aligned}
$$

Step 5: calculating the closeness coefficient $\left(C^{k}\right)$ to the ideal solution.

The separation measure $S^{k^{+}}$determines the closeness of an alternative to the ideal positive. At the same time, $S^{k^{+}}$also determines how far the alternative is from the ideal negative. This leads to a dilemma as to which separation measure among these two is of best use. The relative closeness coefficient is used to resolve the dilemma and is presented in the equation below:

$$
C^{k}=\frac{S^{k^{-}}}{S^{k^{+}}+S^{k^{-}}}, \quad 0 \leq C^{k} \leq 1
$$

The relative closeness coefficient provides a higher rank to the alternative that is close to the ideal positive point. The alternatives are ranked in descending order, from best to worst. To rank the alternatives in the ascending order, best to worst the equation (7a) can be replaced by equation (7b):

$$
\frac{S^{k^{+}}}{S^{k^{+}}+S^{k^{-}}}=1-C^{k}
$$

\section{Establishing a threshold for sustainability measurement}

The threshold is the minimum acceptable value below which an entity is said to have failed the sustainability test. Lancker and Nijkamp (2000), strongly argues that only measuring the sustainability score does not indicate anything, unless it is compared with a threshold or reference value. By identifying the threshold, entities are evaluated for growth performance, and it helps in the realization of effective response policies.

Following the method proposed by Afful-Dadzie et al. (2016), a sustainability threshold level needs to be identified. This is done in a way that a hypothetical alternative for the industry standard is added to the original set of alternatives with a total number of alternatives as $\mathrm{k}+1$, and $(\mathrm{k}+1)$ th being the industry alternative. The same method as per TOPSIS is applied to the new set of alternatives, identifying the ideal positive and ideal negative solutions and the relative closeness 
coefficient $C^{s}$. According to Afful-Dadzie et al. (2016), the entities are considered to have failed the sustainability test if the square of the coefficient $C^{k}$ falls below the square of the industry standard closeness coefficient $C^{s}$ and is denoted as:

$$
\left(C^{k}\right)^{2} \geq\left(C^{s}\right)^{2}
$$

In determining the industry standard threshold, the attributes of TOPSIS are maintained as well as competition among the alternatives is also assured.

\section{Numerical Example}

In this study, the sustainability index for MFIs in Pakistan is developed using TOPSIS-based performance ranking procedure. The sustainability score of MFIs is assessed using four different criteria, including; financial self-sufficiency, operational self-sufficiency, depth of outreach and breadth of outreach. A composite sustainability score for MFIs in Pakistan over the year from 2006-2015 is obtained using TOPSIS. Additionally, a threshold level for the sustainability of MFIs over the years is obtained.

The set of alternatives used in this study are the Microfinance institutions working in Pakistan. Column 2 in Table 2 provides a list of criteria, where $\mathrm{C} 1$ is financial self-sufficiency, $\mathrm{C} 2$ is operational self-sufficiency, $\mathrm{C} 3$ is the depth of outreach measured by average loan balance per borrower, and $\mathrm{C} 4$ is the breadth of outreach approximated by number of active borrowers, for assessing the sustainability score of MFIs. Among these four criteria's C1, C2, and C4 are designated as benefits or "more is better" criteria, which indicates that MFI is advancing towards a higher level of sustainability when FSS, OSS, and breadth of outreach (measured by the number of active borrowers) increases (Bhanot et al., 2015). On the other hand, the increase in average loan balance per borrower weakens the social role of MFIs. Smaller loan size implies that MFIs are more committed towards their social goal of poverty outreach (Cervelló-Royo et al., 2017). Therefore, C3 is designated as "less is better criteria," which indicates that as the depth of outreach (measured by average loan balance per borrower) decreases, MFI become more sustainable. Following Bhanot et al. (2015), FSS and OSS are in percent terms, while ALPB and NAB are absolute figures, so they were transformed using the natural logarithm functions. Following equation 1 the alternatives and criteria are used to develop a normalized decision matrix.

Table 2: Criteria and Criteria weights for four dimensions of sustainability

\begin{tabular}{lll}
\hline Criteria & Symbol & Criteria weight \\
\hline Financial Self-sufficiency & C1 & 0.25 \\
Operational self-sufficiency & C2 & 0.25 \\
Depth of outreach & C3 & 0.25 \\
Breadth of outreach & C4 & 0.25 \\
\hline
\end{tabular}

In the next step, the importance of each criterion in the decision matrix is calculated by multiplying weights with the normalized decision matrix as shown in Equation (2). Column 3 of Table 2 shows the importance of weight assigned to all the four criteria of sustainability. In the current study, the sustainability of MFI is a construct based on "double bottom line" (Gutiérrez-Nieto et al., 2009), which indicates that MFIs are considered sustainable when they achieve both financial sustainability and outreach. Therefore, each criterion in the current study is assigned equal weights. Moreover, Bhanot et al. (2015) determine the sustainability score of MFIs in India by assigning equal weights to all the indicators of sustainability. Bilbao-Terol et al. (2014) use TOPSIS for assessing the sustainability of government bond funds and have applied equal weights of 0.25 to all the criteria. Additionally, Böhringer and Jochem (2007) stated that there are no general rules for weighting and the criteria which is more important than others should be assigned more weight.

The criterion weight for financial self-sufficiency, operational self-sufficiency, depth of outreach, and breadth of outreach is 0.25 respectively. The weights obtained are then used in the TOPSIS method to determine the ideal positive, and ideal negative solution based on "more is better" and "less is better criteria" by following equation (3) and (4).

Additionally, the distance from the positive ideal and negative ideal for each alternative are computed using equation (5) and (6). The relative closeness of an alternative to the ideal solution is determined, and all the alternatives are ranked accordingly. The best alternative is the one which is farthest from the negative ideal and closest to the positive ideal. The composite score $C^{k}$ is obtained by using equation (7a) which help in ranking the organizations from best to worst in the descending order.

Table 3 provides the sustainability score of all MFIs in Pakistan for the year 2006-2015. The sustainability score of MFIs for each year under study and their respective rank in that year are presented in the adjacent column. It is important to note the data obtained for the study is unbalanced, and some MFIs tend not to report data over one or more years, so they were dropped for that respective year. According to Afful-Dadzie et al. (2016), the sustainability score obtained using TOPSIS lies between 0 and 1 , where MFI closest to 0 tend to have lowest sustainable score and MFI having a sustainability score near or equal to 1 have the highest sustainability score.

It is evident from Table 3 that the sustainability score of MFIs vary across the year and their respective ranks depend on their final composite score for the respective year. ASA Pakistan has the highest sustainability score and has the highest rank for three years. Moreover, Villagers development organization has the lowest sustainability score for 2015 and is 
ranked last among all the competing organizations. It is also observed that the sustainability rank of several MFIs has changed over the years depending upon their sustainability performance. For example, the Safco support fund has increased their focus on all the four indicators and their sustainability rank increase from 26, in 2014, to 5, in 2015. Similarly, a drop-down is observed in the rank of Sindh rural support program over the year 2015 as compared to the year 2014 and 2013.

The results shown in Table 3 are merely the scores and the ranks of MFIs, and these do not determine whether MFI is sustainable or not. Lancker and Nijkamp (2000), states that "a given indicator does not say anything about sustainability unless a reference value such as a threshold is set for it." In order words, the prerequisite for sustainability is to achieve a minimum acceptable level. A threshold level needs to be defined to answer the sustainability question. When an MFI falls below this threshold level, it can be deemed to have failed a sustainability test. This is achieved by setting a standard value for all criteria which need to be fulfilled by an alternative. Moreover, Arrow et al. (2012) emphasized that firms are considered sustainable when their progress is improved with time.

In this study, minimum standard values for each criterion to a hypothetical alternative are assigned which help in measuring the overall relative closeness coefficient to determine the threshold level for further comparison. The minimum standard value for each criterion obtained from literature and prudential regulations for MFIs are presented in Table 4 . Financial self-sufficiency ratio has a minimum standard value of 100 percent which denotes that MFIs are able to cover their cost without depending on subsidized funding and may continue on a going concern (CGAP, 2004). OSS of more than 100 percent denotes that operating revenues of MFIs exceed their operating expenses, and is a standard measure used by Bhanot et al. (2015) and CGAP (2004). According to prudential regulations of Microfinance Banks, issued by State Bank of Pakistan, the maximum exposure for both general and microenterprise loan shall not exceed PKR 500,000. Additionally, the scale parameter for number of active borrowers of an MFI shall be 10,000 and above as an indication of MFI sustainability (Bhanot et al., 2015).

Table 4: Sustainability criteria threshold

\begin{tabular}{llll}
\hline Sr.no & Criteria & Symbol & Threshold level \\
\hline 1 & Financial self-sufficiency & C1 & $100 \%$ \\
2 & $\begin{array}{l}\text { Operational self-sufficiency } \\
\text { Depth of outreach (average loan balance per }\end{array}$ & C 3 & $\begin{array}{l}\text { Maximum exposure amount shall not } \\
\text { exceed PKR 500,000 }\end{array}$ \\
& $\begin{array}{l}\text { borrower) } \\
\text { Breadth of outreach (number of active } \\
\text { borrowers) }\end{array}$ & C4 & Greater than or equal to 10,000 \\
\hline
\end{tabular}

Industry standard alternative value for the square of relative closeness coefficient is denoted as $\left(C^{s}\right)^{2}$. For an MFI to be sustainable, it must follow the criteria mentioned in equation (8). It is important to mention here that the composite industry standard value for $\left(C^{S}\right)^{2}$ varies across different year. This happens in TOPSIS because the values for the ideal positive and negative solutions are derived using data for the same alternatives which changes over the years. (AffulDadzie et al., 2016). The change in the square of relative closeness coefficient of 2015 can differ from 2014. For example, Table 5 shows that the square of relative closeness coefficient of 2015 has a value of 0.070 whereas the value for 2014 is 0.090 .

It is to be noted that if the threshold for 2015 is lower, all MFIs may not be considered to have passed the sustainability test. This may be true only if all the alternatives under evaluation outperforms industry standard for all the criteria. In a situation where all the alternatives fall below the industry standard, $\left(C^{s}\right)^{2}$ will become the ideal positive solution for all the alternatives, and all the alternatives are considered to have failed the sustainability test (Afful-Dadzie et al., 2016).

Table 5: Industry standard level for MFIs in Pakistan for the year 2006-2015

\begin{tabular}{ccc}
\hline Year & $\begin{array}{c}\text { Industry threshold } \\
C^{s}\end{array}$ & $\left(C^{s}\right)^{2}$ \\
\hline 2015 & 0.265 & 0.070 \\
\hline 2014 & 0.301 & 0.090 \\
\hline 2013 & 0.323 & 0.104 \\
\hline 2012 & 0.516 & 0.267 \\
\hline 2011 & 0.484 & 0.234 \\
\hline 2010 & 0.594 & 0.352 \\
\hline 2009 & 0.472 & 0.223 \\
\hline 2008 & 0.433 & 0.187 \\
\hline 2007 & 0.413 & 0.171 \\
\hline 2006 & 0.588 & 0.346 \\
\hline
\end{tabular}

\footnotetext{
${ }^{1}$ As per Prudential regulations, 2014 issued by State Bank of Pakistan for Microfinance institutions in Pakistan. 
In addition to the above, Arrow et al. (2012) argued that sustainability might be truly represented when an entity passing the sustainability test improve its performance over time. Figure 1 provides the sustainability performance score for MFIs in Pakistan from the year 2006-2015. The sustainability threshold level for each year is measured and is presented in Table 5. The sustainability performance level of MFIs has increased over the years. In 2006, only 23.5 percent of MFIs working in Pakistan were sustainable. The sustainability level of MFIs increased over the years, and in 2014 almost 92 percent of MFIs were at the sustainability front. The sustainability level of MFIs shows a slight decline in 2015 as 89 percent of MFIs were sustainable.

MFIs in Pakistan have improved their sustainability performance over the years. This has been done by focusing on all the four indicators including FSS, OSS, ALPB, and NAB. Additionally, the policy makers have also emphasized to achieve an increase in financial sustainability by tightening the controls on MFIs. Moreover, the State Bank of Pakistan had a target to achieve the millennium development goal of reaching 10 million borrowers by the end of 2015 (Rauf and Mahmood, 2009; Saad et al., 2018; Saeed and Kayani, 2018; Samaila et al., 2018). Although MFIs in Pakistan does not achieve the target, the outreach has reached up to 3.9 million. This has contributed to an increase in sustainability score of MFIs. Additionally, the majority of MFIs in Pakistan have achieved FSS and OSS ratio of 100 percent in 2015 which has also contributed towards a higher sustainability score.

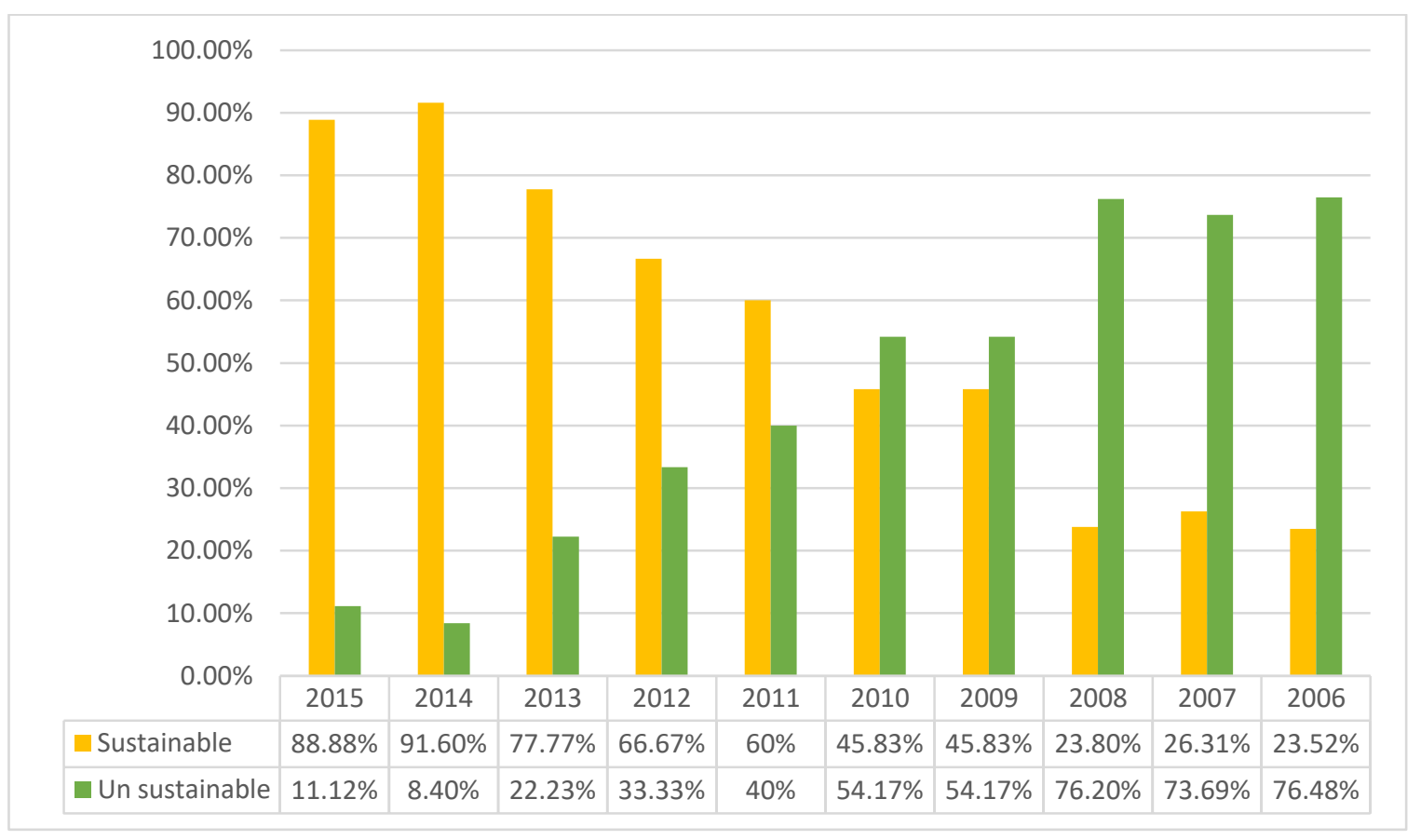

Figure 1 Sustainability threshold performance of MFIs for 2006-2015

\section{CONCLUSION}

Sustainability measurement of MFIs has become a serious issue over the past years. This study is a unique attempt to resolve the issue, by focusing on attaining a double bottom line of financial sustainability and outreach simultaneously. The approach used in this paper considers the complexity of MFI sustainability problem and include financial selfsufficiency, operational self-sufficiency, depth of outreach and breadth of outreach. Composite sustainability score of MFIs is obtained for the year 2006-2015 by using TOPSIS.

Additionally, a threshold level for the sustainability of MFI is identified by assigning minimum industry standard values of each criterion for developing a hypothetical alternative. The relative closeness coefficient of the hypothetical alternative became the threshold and was used for comparison. Due to the significance of each criterion used in this study, all were considered equally important and were assigned equal weights in sustainability measurement. This way, organizations with relative closeness coefficient below that of the industry standard alternative are deemed to have failed the sustainability test. The sustainability performance of MFIs in Pakistan for the year 2006-2015 is presented in a figure for a better understanding.

The sustainability threshold level for MFIs over the year 2006-2015 is determined. The square of the relative closeness coefficient was compared with the industry standard. The sustainability threshold level for MFIs during 2006-2015 are $0.34,0.17,0.18,0.22,0.35,0.23,0.26,0.10,0.09$, and 0.07 respectively. The result shows that over the year number of MFIs passing the sustainability test have increased with 91 percent of MFIs passing the sustainability test in 2014. Although, the percentage declines in 2015, but overall MFIs are progressing well on the sustainability front. 
Future research may determine the sustainability score of MFIs by assigning weights to each criterion through Rating agencies or experts. Moreover, the scope of the study may be enhanced by evaluating sustainability score across countries and comparing them. The future research may use the sustainability score to identify other factors which affect the growth performance of MFIs.

\section{REFERENCES}

1. Afful-Dadzie, A., E. Afful-Dadzie and C. Turkson, 2016. A topsis extension framework for re-conceptualizing sustainability measurement. Kybernetes, 45(1): 70-86. https://doi.org/10.1108/K-04-2015-0106

2. Arrow, K.J., P. Dasgupta, L.H. Goulder, K.J. Mumford and K. Oleson, 2012. Sustainability and the measurement of wealth. Environment and development economics, 17(3): 317-353. https://doi.org/10.1017/S1355770X12000137

3. Bhanot, D., V. Bapat and J. Connelly, 2015. Sustainability index of micro finance institutions (mfis) and contributory factors. International Journal of Social Economics, 42(4). https://doi.org/10.1108/IJSE-01-2014-0001

4. Bilbao-Terol, A., M. Arenas-Parra, V. Cañal-Fernández and J. Antomil-Ibias, 2014. Using topsis for assessing the sustainability of government bond funds. Omega, 49: 1-17.

https://doi.org/10.1016/j.omega.2014.04.005

5. Böhringer, C. and P.E. Jochem, 2007. Measuring the immeasurable-a survey of sustainability indices. Ecological economics, 63(1): 1-8.https://doi.org/10.1016/j.ecolecon.2007.03.008

6. Boran, F.E., S. Genç, M. Kurt and D. Akay, 2009. A multi-criteria intuitionistic fuzzy group decision making for supplier selection with topsis method. Expert Systems with Applications, 36(8): 1136311368.https://doi.org/10.1016/j.eswa.2009.03.039

7. Cervelló-Royo, R., F. Guijarro and V. Martinez-Gomez, 2017. Social performance considered within the global performance of microfinance institutions: A new approach. Operational Research: 1-19. https://doi.org/10.1007/s12351-017-0360-3

8. CGAP, 2003. Microfinance consensus guidelines.

9. CGAP, 2004. Key principles of microfinance. CGAP, WASHINGTON.

10. Christen, R.P., 1995. Maximizing the outreach of microenterprise finance: An analysis of successful microfinance programs. Center for Development Information and Evaluation, US Agency for International Development.

11. Deng, H., C.-H. Yeh and R.J. Willis, 2000. Inter-company comparison using modified topsis with objective weights. Computers \& Operations Research, 27(10): 963-973. https://doi.org/10.1016/S0305-0548(99)00069-6

12. Gutiérrez-Nieto, B., C. Serrano-Cinca and C.M. Molinero, 2009. Social efficiency in microfinance institutions. J Oper Res Soc, 60(1): 104-119.https://doi.org/10.1057/palgrave.jors.2602527

13. Hermes, N., R. Lensink and A. Meesters, 2011. Outreach and efficiency of microfinance institutions. World Development, 39(6): 938-948.https://doi.org/10.1016/j.worlddev.2009.10.018

14. Hwang, C.-L. and K. Yoon, 1981. Methods for multiple attribute decision making. In: Multiple attribute decision making. Springer: pp: 58-191.https://doi.org/10.1007/978-3-642-48318-9 3

15. Lancker, E. and P. Nijkamp, 2000. A policy scenario analysis of sustainable agricultural development options: A case study for nepal. Impact Assessment and Project Appraisal, 18(2): 111-124. https://doi.org/10.3152/147154600781767493

16. Louis, P. and B. Baesens, 2013. Do for-profit microfinance institutions achieve better financial efficiency and social impact? A generalised estimating equations panel data approach. J Dev Effect, 5(3): 359380.https://doi.org/10.1080/19439342.2013.822015

17. Mia, M.A., S. Nasrin and Z. Cheng, 2015. Quality, quantity and financial sustainability of microfinance: Does resource allocation matter? Quality \& Quantity: 1-14. https://doi.org/10.1007/s11135-015-0205-1

18. Nanayakkara, G., 2012. Measuring the performance of microfinancing institutions: A new approach. South Asia Economic Journal, 13(1): 85-104.https://doi.org/10.1177/139156141101300105

19. Okumu, L.J., 2007. The microfinance industry in uganda: Sustainability, outreach and regulation. Stellenbosch: University of Stellenbosch.

20. Rai, A.K. and S. Rai, 2012. Factors affecting financial sustainability of microfinance institutions. Journal of Economics and Sustainable Development, 3(6): 1-9.

21. Rauf, S.A. and T. Mahmood, 2009. Growth and performance of microfinance in pakistan. Pakistan Economic and Social Review: 99-122. 
22. Rismayadi, B. and M. Maemunah, 2018. Creative economy to increase community revenue based on tourism object, medalsari village, pangkalan district karawang regency. Journal of Accounting, Business and Finance Research, 3(1): 28-35.https://doi.org/10.20448/2002.31.28.35

23. Riyanti, M.T., 2018. Development of learning devices commercial graphic based planning project. International Journal of Education, Training and Learning, 2(1): 1-6. https://doi.org/10.33094/6.2017.2018.21.1.6

24. Rosli, A. and T.I. Siong, 2018. Determinants of customer satisfaction towards services provided by agencies in urban transformation centre (utc). International Journal of Economics, Business and Management Studies, 5(1): 9-15.https://doi.org/10.20448/802.51.9.15

25. Rotova, N.A., 2018. Development of independence among future primary school teachers by applying interactive learning methods. Journal of Education and e-Learning Research, 5(2): 118-121. https://doi.org/10.20448/journal.509.2018.52.118.121

26. Saad, S., I. Umer and F. Ahmed, 2018. An empirical evidence of over reaction hypothesis on karachi stock exchange (kse). Asian Economic and Financial Review, 8(4): 449-465. https://doi.org/10.18488/journal.aefr.2018.84.449.465

27. Saeed, N. and A.I. Kayani, 2018. Role of college principals in promoting quality of education in district kotli aj\&k. Asian Journal of Contemporary Education, 2(2): 149-158. https://doi.org/10.18488/journal.137.2018.22.149.158

28. Samaila, M., O.C. Uzochukwu and M. Ishaq, 2018. Organizational politics and workplace conflict in selected tertiary institutions in edo state, nigeria. International Journal of Emerging Trends in Social Sciences, 4(1): 2641.https://doi.org/10.20448/2001.41.26.41

29. Shih, H.-S., H.-J. Shyur and E.S. Lee, 2007. An extension of topsis for group decision making. Mathematical and Computer Modelling 45(7-8): 801-813.https://doi.org/10.1016/j.mcm.2006.03.023

30. Wanke, P., M.A.K. Azad and C. Barros, 2016. Predicting efficiency in malaysian islamic banks: A two-stage topsis and neural networks approach. Research in International Business and Finance, 36: 485498.https://doi.org/10.1016/j.ribaf.2015.10.002

31. Yaron, J., 1994. What makes rural finance institutions successful? The World Bank Research Observer, 9(1): 4970.https://doi.org/10.1093/wbro/9.1.49 
Table 3: Sustainability score of MFIs

\begin{tabular}{|c|c|c|c|c|c|c|c|c|c|c|c|c|c|c|c|c|c|c|c|c|}
\hline MFI & 2015 & Rank & 2014 & Rank & 2013 & Rank & 2012 & Rank & 2011 & Rank & 2010 & Rank & 2009 & Rank & 2008 & Rank & 2007 & Rank & 2006 & Rank \\
\hline$\overline{\text { ASA-P }}$ & 0.92 & 1 & 0.93 & 1 & 0.86 & 1 & 0.90 & 2 & 0.96 & 1 & 0.75 & 3 & 0.36 & 18 & - & - & - & - & - & - \\
\hline PRSP & 0.83 & 2 & 0.75 & 3 & 0.85 & 2 & 0.91 & 1 & 0.55 & 11 & 0.54 & 14 & 0.56 & 8 & 0.36 & 9 & 0.21 & 13 & 0.34 & 10 \\
\hline SUNGI & 0.74 & 3 & 0.78 & 2 & 0.78 & 3 & - & - & - & - & 0.80 & 1 & 0.55 & 10 & 0.67 & 2 & 0.36 & 6 & - & - \\
\hline TRDP & 0.61 & 4 & 0.65 & 5 & 0.66 & 5 & 0.78 & 4 & 0.62 & 4 & 0.73 & 4 & 0.72 & 2 & 0.24 & 19 & 0.15 & 16 & 0.13 & 17 \\
\hline$\overline{\text { SAFCO }}$ & 0.54 & 5 & 0.33 & 26 & 0.33 & 27 & 0.51 & 19 & 0.56 & 8 & 0.54 & 15 & 0.45 & 13 & 0.31 & 12 & 0.26 & 10 & 0.28 & 12 \\
\hline ORIX & 0.53 & 6 & 0.45 & 12 & 0.32 & 29 & 0.51 & 18 & 0.50 & 15 & 0.62 & 10 & 0.70 & 3 & 0.57 & 3 & 0.49 & 3 & 0.65 & 2 \\
\hline RCDS & 0.52 & 7 & 0.48 & 11 & 0.65 & 7 & 0.71 & 6 & 0.62 & 5 & 0.71 & 5 & 0.48 & 11 & - & - & - & - & - & - \\
\hline NRSP & 0.52 & 8 & 0.54 & 6 & 0.66 & 6 & 0.61 & 14 & 0.65 & 3 & 0.71 & 6 & 067 & 4 & 0.54 & 4 & 0.43 & 5 & 0.52 & 5 \\
\hline GBTI & 0.49 & 9 & 0.72 & 4 & 0.45 & 14 & 0.80 & 3 & - & - & - & - & - & - & - & - & - & - & - & - \\
\hline TMF-B & 0.49 & 10 & 0.48 & 10 & 0.52 & 12 & 0.72 & 5 & 0.60 & 6 & 0.65 & 9 & 0.40 & 16 & 0.24 & 18 & 0.15 & 17 & 0.22 & 14 \\
\hline NRSP-B & 0.48 & 11 & 0.41 & 14 & 0.53 & 10 & 0.66 & 9 & 0.56 & 10 & - & - & - & - & - & - & - & - & - & - \\
\hline KBL & 0.47 & 12 & 0.49 & 9 & 0.53 & 11 & 0.62 & 10 & 0.56 & 9 & 0.67 & 7 & 0.59 & 5 & 0.33 & 11 & 0.28 & 9 & 0.57 & 8 \\
\hline SRSP & 0.44 & 13 & 0.54 & 7 & 0.72 & 4 & 0.62 & 11 & 0.11 & 25 & 0.09 & 24 & 0.33 & 20 & 0.40 & 6 & 0.22 & 12 & - & - \\
\hline DAMEN & 0.43 & 14 & 0.50 & 8 & 0.54 & 9 & 0.69 & 7 & 0.54 & 12 & 0.65 & 8 & 0.57 & 6 & 0.49 & 5 & 0.45 & 4 & 0.48 & 6 \\
\hline FMFB & 0.42 & 15 & 0.36 & 20 & 0.40 & 17 & 0.56 & 16 & 0.46 & 16 & 0.56 & 12 & 0.55 & 9 & 0.37 & 7 & 0.35 & 7 & 0.64 & 4 \\
\hline AKHUWAT & $\Gamma 0.41$ & 16 & 0.39 & 17 & 0.58 & 8 & 0.48 & 22 & 0.31 & 22 & 0.37 & 20 & 0.25 & 22 & 0.28 & 14 & 0.16 & 14 & 0.30 & 11 \\
\hline SAATH & 0.41 & 17 & 0.35 & 21 & 0.37 & 20 & - & - & - & - & - & - & - & - & - & - & - & - & - & - \\
\hline JWS & 0.40 & 18 & 0.38 & 18 & 0.44 & 15 & 0.61 & 13 & 0.58 & 7 & 0.62 & 11 & 0.56 & 7 & - & - & - & - & - & - \\
\hline KASHAF & 0.40 & 19 & 0.44 & 13 & 0.47 & 13 & 0.62 & 12 & 0.43 & 17 & 0.50 & 16 & 0.38 & 17 & 0.30 & 13 & 0.75 & 2 & 0.95 & 1 \\
\hline CSC & 0.38 & 20 & 0.41 & 15 & 0.38 & 19 & 0.54 & 17 & 0.52 & 13 & 0.33 & 22 & 0.32 & 21 & 0.35 & 10 & 0.32 & 8 & 0.17 & 16 \\
\hline SVDP & 0.38 & 21 & 0.32 & 32 & 0.31 & 30 & - & - & - & - & - & - & - & - & - & - & - & - & - & - \\
\hline FINCA & 0.36 & 22 & 0.34 & 25 & 0.36 & 25 & 0.41 & 24 & 0.32 & 21 & 0.31 & 23 & 0.25 & 23 & 0.26 & 15 & - & - & - & - \\
\hline MOJAZ & 0.35 & 23 & 0.32 & 29 & 0.33 & 28 & - & - & - & - & - & - & - & - & - & - & - & - & - & - \\
\hline FFO & 0.35 & 24 & 0.32 & 30 & 0.23 & 32 & 0.46 & 23 & 0.26 & 24 & - & - & - & - & - & - & - & - & - & - \\
\hline OPD & 0.34 & 25 & 0.39 & 16 & 0.37 & 22 & - & - & - & - & - & - & - & - & - & - & - & - & - & - \\
\hline BRAC-P & 0.34 & 26 & 0.34 & 23 & 0.37 & 21 & 0.49 & 21 & 0.41 & 19 & 0.49 & 17 & 0.42 & 14 & 0.09 & 21 & - & - & - & - \\
\hline AGAHE & 0.34 & 27 & 0.37 & 19 & 0.36 & 23 & - & - & - & - & - & - & - & - & - & - & - & - & - & - \\
\hline POMFB & 0.32 & 28 & 0.31 & 33 & 0.14 & 35 & 0.50 & 20 & 0.52 & 14 & 0.47 & 18 & 0.33 & 19 & 0.26 & 17 & 0.16 & 15 & 0.45 & 7 \\
\hline U-BANK & 0.31 & 29 & 0.15 & 35 & 0.02 & 36 & 0.09 & 27 & - & - & - & - & 0.12 & 24 & 0.17 & 20 & 0.07 & 18 & 0.21 & 15 \\
\hline SRDO & 0.31 & 30 & 0.35 & 22 & 0.21 & 33 & - & - & - & - & - & - & - & - & - & - & - & - & - & - \\
\hline NAYMET & 0.31 & 31 & 0.33 & 27 & 0.34 & 26 & - & - & - & - & - & - & - & - & - & - & - & - & - & - \\
\hline AMRDO & 0.30 & 32 & 0.34 & 24 & 0.36 & 24 & - & - & - & - & - & - & - & - & - & - & - & - & - & - \\
\hline AMBL & 0.26 & 33 & 0.32 & 31 & 0.18 & 34 & 0.26 & 25 & 0.33 & 20 & 035 & 21 & 0.42 & 15 & 0.26 & 16 & 0.06 & 18 & 0.34 & 9 \\
\hline OCT & 0.25 & 34 & 0.13 & 36 & 0.38 & 18 & 0.61 & 15 & 0.77 & 2 & 0.78 & 2 & 0.82 & 1 & 0.90 & 1 & 0.90 & 1 & 0.64 & 3 \\
\hline SRSO & 0.19 & 35 & 0.32 & 28 & 0.41 & 16 & 0.68 & 8 & 0.43 & 18 & 0.55 & 13 & - & - & - & - & - & - & - & - \\
\hline VDO & 0.16 & 36 & 0.28 & 34 & 0.24 & 31 & - & - & - & - & - & - & - & - & - & - & - & - & - & - \\
\hline ASASAH & - & - & - & - & - & - & 0.26 & 26 & 0.27 & 23 & 0.43 & 19 & 046 & 12 & 0.37 & 8 & 0.23 & 11 & 0.25 & 13 \\
\hline
\end{tabular}

